\title{
Purification of Starch Granules from Arabidopsis Leaves and Determination of Granule- Bound Starch Synthase Activity
}

Tomás Albi, M. Isabel Ortiz-Marchena, M. Teresa Ruiz, José M. Romero and Federico Valverde*

Instituto de Bioquímica Vegetal y Fotosíntesis, Consejo Superior de Investigaciones Científicas and Universidad de Sevilla, Seville, Spain

*For correspondence: federico.valverde@ibvf.csic.es

[Abstract] Starch constitutes the most important carbon reserve in plants and is composed of branched amylopectin and linear amylose. The latter is synthesized exclusively by the GranuleBound Starch Synthase (GBSS, EC 2.4.1.21). Here we report a readily reproducible, specific and highly sensitive protocol, which includes the isolation of intact starch granules from Arabidopsis thaliana leaves and the subsequent determination of GBSS activity. We have applied this method to study GBSS activity in diurnal cycles in vegetative growth and during the photoperiodic transition to flowering in Arabidopsis (Tenorio et al., 2003; Ortiz-Marchena et al., 2014).

\section{Materials and Reagents}

1. Plant materials

Note: Arabidopsis thaliana (A. thaliana) were grown in controlled cabinets on peat-based compost.

2. Liquid $\mathrm{N}_{2}$

3. HEPES (Sigma-Aldrich, catalog number: H4034)

4. Potassium hydroxide pellets (Panreac Applichem, catalog number: A0566)

5. Triton $^{\mathrm{TM}} \mathrm{X}-100$ (Sigma-Aldrich, catalog number: $\mathrm{X} 100$ )

6. Miracloth (Merck KGaA, catalog number: 475855)

7. Percol $^{\circledR}$ (Sigma-Aldrich, catalog number: P1644)

8. Glycogen (from rabbit liver Type III) (Sigma-Aldrich, catalog number: G8876)

9. Tricine (Sigma-Aldrich, catalog number: T0377)

10. Potassium acetate (Sigma-Aldrich, catalog number: P1147)

11. DL-Dithiothreitol (DTT) (Sigma-Aldrich, catalog number: D0632)

12. Ethylenediaminetetraacetic acid disodium salt dihydrate (EDTA) (Sigma-Aldrich, catalog number: E5134)

13. Sodium hydroxide pellets (Panreac Applichem, catalog number: 131687)

14. Maltotriose (Sigma-Aldrich, catalog number: M8378) 
15. Adenosine 5' diphospho, [D-glucose- $\left.{ }^{14} \mathrm{C}(\mathrm{U})\right]$ ammonium salt (ADP [U-14 C] glucose) (American Radiolabeled Chemicals, catalog number: ARC 3297)

16. Methanol (CARLO ERBA Reagents, catalog number: 412532)

17. Potassium chloride (AppliChem $\mathrm{GmbH}$, catalog number: A2939)

18. Ecolite $(+)^{\mathrm{TM}}$ liquid scintillation cocktail (MP Biomedicals, catalog number: 882475)

19. $1 \mathrm{M}$ HEPES-KOH (see Recipes)

20. $1 \mathrm{M}$ Tricine (see Recipes)

21. $0.25 \mathrm{M}$ Potassium acetate (see Recipes)

22. $1 \mathrm{M}$ DTT (see Recipes)

23. $0.5 \mathrm{M}$ EDTA (see Recipes)

24. 0.1 M Maltotriose (see Recipes)

25. $3 \mathrm{M} \mathrm{KCl}$ (see Recipes)

26. $20 \mathrm{mg} / \mathrm{ml}$ Glycogen solution (see Recipes)

27. Extraction buffer (see Recipes)

28. Percoll buffer (see Recipes)

29. Washing buffer (see Recipes)

30. Precipitation buffer (see Recipes)

\section{Equipment}

1. Small mortar and pestle

2. $1.5 \mathrm{ml}$ microfuge tubes

3. Automatic pipettes

4. Precision scale

5. Centrifuge (Eppendorf, model: $5810 \mathrm{R}$ )

6. Microcentrifuge (Eppendorf, model: 5424)

7. Scintillation Counter (Beckman Coulter, model: LS 6000 IC)

8. Scintillation vials (Sigma-Aldrich, catalog number: Z376817)

\section{Procedure}

A. Starch granules isolation

Starch granules were purified following a modification of the Percoll method described by Tenorio et al. (2003).

1. Homogenize $600 \mathrm{mg}$ (fresh weight) of Arabidopsis leaves in a mortar and pestle in the presence of liquid $\mathrm{N}_{2}$ to a fine powder and add $1 \mathrm{ml}$ of extraction buffer. Leaf material was 
collected from fully developed rosette leaves from at least three different plants at growth stage 3.50 [according to Boyes et al. (2001)].

2. Filter the homogenate through two layers of Miracloth on $15 \mathrm{ml}$ Falcon-type tubes.

3. Add $5 \mathrm{ml}$ of Percoll buffer $\left(4^{\circ} \mathrm{C}\right)$ to the filtrate and mix.

4. Centrifuge samples for $5 \mathrm{~min}, 805 \times \mathrm{g}$ at $4{ }^{\circ} \mathrm{C}$ (2,000 rpm, Eppendorf-5810 R centrifuge) and discard the supernatant.

5. Wash the pellet by resuspension in $5 \mathrm{ml}$ washing buffer $\left(4^{\circ} \mathrm{C}\right)$, centrifuge as in step $\mathrm{A} 4$ and discard the supernatant. Repeat three times.

6. Air-dry the pellet (do not let it dry completely) containing the starch granules (Figure 1) and use it immediately for determination of GBSS activity as described below.

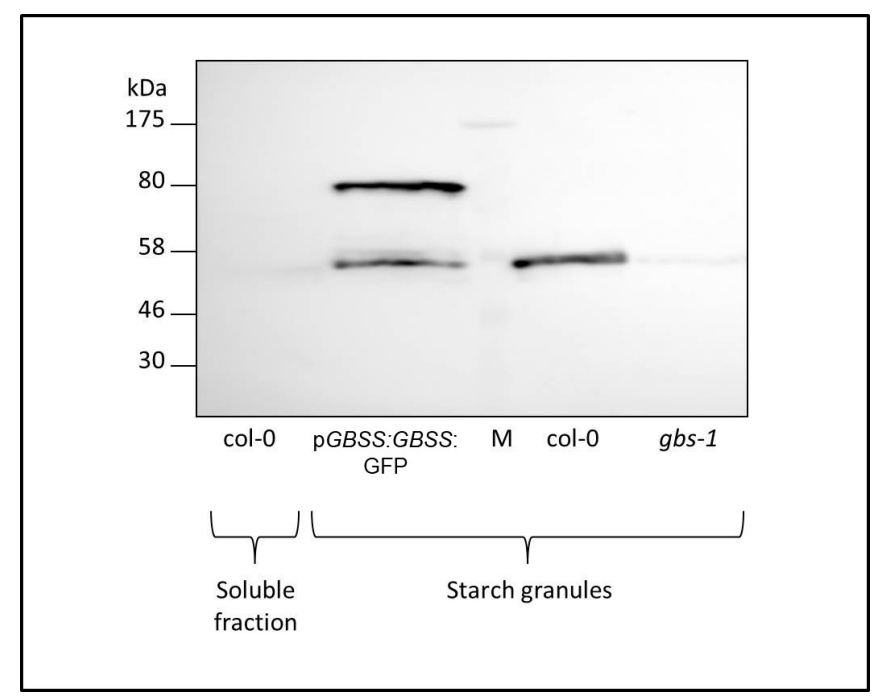

Figure 1. Immunodetection of GBSS in starch granules isolated from Arabidopsis Col-

0 leaves. Western blot employing GBSS-specific antibodies in protein extracts from starch granules isolated from wild-type (Col-0), GBSS mutant (gbs-1) and a recombinant line in which GBSS is fused to GFP. Molecular Mass (MM) markers are shown in kDa (left). Notice GBSS MM around $55 \mathrm{kDa}$ and GBSS-GFP around $80 \mathrm{kDa}$. GBSS detection is strictly associated to starch granules fractions (three rightmost lanes) and cannot be detected in a soluble protein fraction (leftmost lane).

B. GBSS activity assay

The granule-bound starch synthase activity was immediately measured from freshly purified starch granules.

1. Starch granules were resuspended in $200 \mu \mathrm{l}$ of $100 \mathrm{mM}$ Tricine ( $\mathrm{pH}$ 8.4), $25 \mathrm{mM}$ potassium acetate, $10 \mathrm{mM}$ DTT, $5 \mathrm{mM}$ EDTA and $10 \mathrm{mM}$ ADP [U-14 C] glucose (specific activity 7.4 $\mathrm{GBq} / \mathrm{mol})$. 
2. $100 \mu \mathrm{l}$ aliquot was quickly extracted and boiled for $5 \mathrm{~min}$ to represent DPMtotal of the assay.

3. The rest of the reaction was incubated at $30^{\circ} \mathrm{C}$ for $20-60 \mathrm{~min}$.

4. The reaction was stopped by boiling for $5 \mathrm{~min}$.

5. Starch granules were precipitated by adding $1.875 \mathrm{ml}$ of precipitation buffer and $25 \mu \mathrm{l}$ of glycogen solution as an inert carrier to increase recovery from alcohol precipitation.

6. Tubes were centrifuged $3 \mathrm{~min}, 2,000 \times \mathrm{g}$ at $4{ }^{\circ} \mathrm{C}$ (4,615 rpm, Eppendorf-5424) and the supernatant discarded.

7. The pellet was resuspended in $0.2 \mathrm{ml}$ deionized water and washed by an additional precipitation with $1.750 \mathrm{ml}$ precipitation buffer without glycogen.

8. Tubes were centrifuged as in step B5. The pellet was air-dried for a short time, resuspended in $1 \mathrm{ml}$ of deionized water and transferred into an appropriate scintillation vial.

9. $5 \mathrm{ml}$ of EcoLite liquid scintillation cocktail was added to enhance ${ }^{14} \mathrm{C}$ counting efficiency.

10. Finally, the radioactivity incorporated into the starch granules was determined with a scintillation counter.

11. GBSS activity (see Table 1 and Figure 2 ) is calculated by using the following formula:

Activity $(\mathrm{nmol} / \mathrm{min} / \mathrm{gfw})=\frac{\text { DPMreac } * n m o l}{\text { DPMzero } * t * g f w}$

DPMreac $=$ disintegration per minute of the reaction sample minus DPM blank (Table 1)

$\mathrm{nmol}=$ nmoles of ADP $\left[\mathrm{U}-{ }^{14} \mathrm{C}\right]$ glucose $(1,000 \mathrm{nmol}$ according to the protocol $)$

DPMtotal $=$ total DPM of added ADP $\left[-{ }^{14} \mathrm{C}\right]$ glucose (step B2)

$\mathrm{t}=$ reaction time $(\mathrm{min})(20-60 \mathrm{~min}$ according to the protocol)

$\mathrm{gfw}=$ fresh weight $(\mathrm{g})(0.3 \mathrm{~g}$ according to the protocol)

Table 1. Determination of GBSS activity in starch granules from wild type (Col-0) and gbs-1 mutant

\begin{tabular}{|l|c|c|c|c|c|c|c|c|}
\hline Plant & $\begin{array}{c}\text { Blank }^{\mathbf{a}} \\
(\mathrm{DPM})\end{array}$ & $\begin{array}{c}\text { Sample }^{\mathbf{b}} \\
(\mathrm{DPM})\end{array}$ & $\begin{array}{c}\text { DPMtotal }^{\mathbf{c}} \\
(\mathrm{DPM})\end{array}$ & $\begin{array}{c}\text { DPMreac }^{\boldsymbol{d}} \\
(\mathrm{DPM})\end{array}$ & $\begin{array}{c}\text { gfw } \\
(\mathrm{g})\end{array}$ & $\begin{array}{c}\text { Reactio } \\
\mathbf{n} \text { time } \\
(\mathrm{min})\end{array}$ & $\begin{array}{c}\text { nmol } \\
\text { ADP-gluc } \\
(\mathrm{nmol})\end{array}$ & $\begin{array}{c}\text { Activity } \\
(\mathrm{nmol} / \mathrm{min} / \mathrm{gfw})\end{array}$ \\
\hline Col-0 & 178.44 & $2,641.02$ & $57,645.40$ & $2,462.58$ & 0.332 & 20 & 1,000 & 6.43 \\
\hline gbs-1 & 193.92 & 197.94 & $57,645.40$ & 4.02 & 0.266 & 20 & 1,000 & 0.01 \\
\hline
\end{tabular}

a. DPM for the blank sample. Blank sample is identical to each sample except that it was stopped at time 0 , so that the reaction was not allowed to start.

b. To simplify, a single sample measurement is shown in Table 1. We recommend calculating data from three independent experiments. Sample DPM correspond to the Disintegration Per Minute at the desired reaction time for each sample (experimental data). 
c. DPMtotal is the total amount of DPM provided by the radiolabelled substrate. It actually represents the maximum of DPM for each sample. According to the above example it consists on the total DPM given by $1,000 \mathrm{nmol}$ of ADP $\left[\mathrm{U}-{ }^{14} \mathrm{C}\right]$ glucose determined for aliquots from step B2.

d. DPMreac $=$ DPMsample minus DPMblank

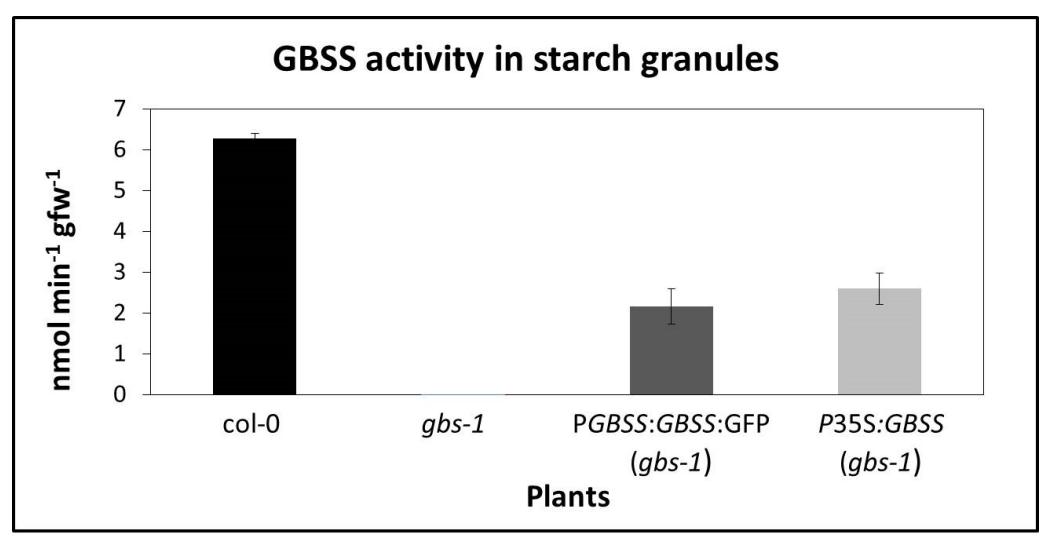

Figure 2. GBSS activity in starch granules from Arabidopsis thaliana leaves. GBSS activity (nmol/min/gfw) in starch granules from wild-type (Col-0), GBSS mutant (gbs-1), GBSS fused to GFP under its own promoter (pGBSS:GBSS:GFP) in gbs-1 background and GBSS expressed under the 35S promoter (P35S:GBSS) in gbs-1 background lines. Values are the average of three independent experiments. Bars indicate the standard deviation $( \pm S E M)$. Starch granules isolation and GBSS activity was carried out as described in text.

\section{Representative data}

1. As shown in Figure 1, a GBSS activity of ca. $6 \mathrm{nmol} / \mathrm{min} / \mathrm{gfw}$ is expected in starch granules isolated from $A$. thaliana ecotype col-0 leaves.

2. Relative SD (expressed as percentage of the mean) fell in the range of 2-14 per cent for samples from three independent experiments.

\section{Notes}

1. Use dischargeable lab ware and appropriate radioactive secure installations and equipment while manipulating $A D P\left[U-{ }^{14} \mathrm{C}\right]$ glucose. 


\section{Recipes}

Note: The given volumes are sufficient for 50 reactions.

1. $1 \mathrm{M}$ HEPES-KOH $(\mathrm{pH} 7.5)$

Mix $59.58 \mathrm{~g}$ HEPES with $175 \mathrm{ml}$ deionized water

Adjust $\mathrm{pH}$ to 7.5 with $\mathrm{KOH}$ pellets

Add deionized water to $250 \mathrm{ml}$

Sterilize through $0.2 \mu \mathrm{m}$ pore diameter filters

Stored at $4{ }^{\circ} \mathrm{C}$

2. $1 \mathrm{M}$ Tricine $(\mathrm{pH} 8.4)$

Mix $4.48 \mathrm{~g}$ Tricine with $20 \mathrm{ml}$ deionized water

Adjust $\mathrm{pH}$ to 8.4 with $\mathrm{KOH}$

Add deionized water to $25 \mathrm{ml}$

Autoclave

Stored at $4{ }^{\circ} \mathrm{C}$

3. $0.25 \mathrm{M}$ Potassium acetate

Mix $1.23 \mathrm{~g}$ Potassium acetate with $40 \mathrm{ml}$ deionized water

Sterilize through $0.2 \mu \mathrm{m}$ pore diameter filters

Stored at Room Temperature (RT)

4. $1 \mathrm{M} \mathrm{DTT}$

Weigh $1.54 \mathrm{~g}$ DTT

Add deionized water to $10 \mathrm{ml}$

Distribute in aliquots and store at $-20^{\circ} \mathrm{C}$

5. $0.5 \mathrm{M}$ EDTA ( $\mathrm{pH} 8.0$ )

Mix $18.61 \mathrm{~g}$ EDTA (disodium, dihydrate) with $80 \mathrm{ml}$ deionized water

Adjust to $\mathrm{pH} 8.0$ with $\mathrm{NaOH}$

Note: It is not easy to dissolve the EDTA. It will not dissolve completely until the $\mathrm{pH}$ is around 8.0.

Autoclave (15 psi, $\left.1-2 \mathrm{~h}, 120^{\circ} \mathrm{C}\right)$

Stored at RT

6. $0.1 \mathrm{M}$ Maltotriose

Weigh $0.2655 \mathrm{~g}$ Maltotriose

Add deionized water to $5 \mathrm{ml}$

Sterilize through $0.2 \mu \mathrm{m}$ pore diameter filters

Distribute in aliquots and store at $-20^{\circ} \mathrm{C}$

7. $3 \mathrm{M} \mathrm{KCl}$

Weigh $2.237 \mathrm{~g}$ of $\mathrm{KCl}$ 
Add deionized water to $10 \mathrm{ml}$

Autoclave (15 psi, 1-2 h, $\left.120^{\circ} \mathrm{C}\right)$

Stored at RT

8. $20 \mathrm{mg} / \mathrm{ml}$ Glycogen solution

Weigh $25 \mathrm{mg}$ of glycogen

Add deionized water to $1.25 \mathrm{ml}$

Stored at $-20^{\circ} \mathrm{C}$

9. Extraction buffer

Mix $2.5 \mathrm{ml} 1 \mathrm{M}$ HEPES-KOH (pH 7.5) with $0.5 \mathrm{ml}$ Triton X-100

Add deionized water to $50 \mathrm{ml}$

Stored at RT

10. Percoll buffer

Mix $12.5 \mathrm{ml} 1 \mathrm{M} \mathrm{HEPES}-\mathrm{KOH}$ (pH 7.5) with $125 \mathrm{ml}$ Percoll

Add deionized water to $250 \mathrm{ml}$

11. Washing buffer

$37.5 \mathrm{ml}$ of $1 \mathrm{M}$ HEPES-KOH $(\mathrm{pH} 7.5)$

Add deionized water to $750 \mathrm{ml}$

12. Precipitation buffer

$150 \mathrm{ml}$ Methanol

Add $9.4 \mathrm{ml} 3 \mathrm{M} \mathrm{KCl}$

Add deionized water to $200 \mathrm{ml}$

Stored at RT

\section{Acknowledgments}

This work was performed with funding from projects CSD2007-00057, BIO2008-02292, and BIO2011-28847-C02-00 (Spanish Ministry of Economy and Competitiveness, MINECO) and Excellence projects P06-CVI-01450 and P08-AGR-03582 (Junta de Andalucía) partially supported by FEDER funding to F. V. and J. M. R. We also acknowledge the TRANSPLANTA consortium Project CONSOLIDER 28317 (MINECO).

\section{References}

1. Boyes, D. C., Zayed, A. M., Ascenzi, R., McCaskill, A. J., Hoffman, N. E., Davis, K. R. and Gorlach, J. (2001). Growth stage-based phenotypic analysis of Arabidopsis: a model for high throughput functional genomics in plants. Plant Cell 13(7): 1499-1510. 
2. Ortiz-Marchena, M. I., Albi, T., Lucas-Reina, E., Said, F. E., Romero-Campero, F. J., Cano, B., Ruiz, M. T., Romero, J. M. and Valverde, F. (2014). Photoperiodic control of carbon distribution during the floral transition in Arabidopsis. Plant Cell 26(2): 565-584.

3. Tenorio, G., Orea, A., Romero, J. M. and Mérida, A. (2003). Oscillation of mRNA level and activity of granule-bound starch synthase I in Arabidopsis leaves during the day/night cycle. Plant Mol Biol 51(6): 949-958. 